\title{
ENHANCED PHOTOCATALYTIC PROPERTIES OF AG-LOADED N-DOPED TIO2 NANOTUBE ARRAYS
}

\author{
Dawei Gao ${ }^{1,2 *}$, Zhenqian Lu', ${ }^{1,2}$ Chunxia Wang², Weiwei $\mathrm{Li}^{2}$, Pengyu Dong ${ }^{3 *}$ \\ ${ }^{1}$ Collaborative Innovation Center for Ecological Building Materials and Environmental Protection Equipments, \\ Yancheng Institute of Technology, Yancheng, 224002, China \\ ${ }^{2}$ School of Textile and Clothing, Yancheng Institute of Technology, Yancheng, 224002, China \\ ${ }^{3}$ Key Laboratory for Advanced Technology in Environmental Protection of Jiangsu Province/Jiangsu Collaborative Innovation Center for Ecological Building \\ Materials and Environmental Protection Equipments, Yancheng Institute of Technology, Yancheng, 224051, China \\ Email: gdw8668@163.com, dongpy11@gmail.com
}

\begin{abstract}
:
Highly ordered $\mathrm{TiO}_{2}$ nanotube $\left(\mathrm{TiO}_{2} \mathrm{NT}\right)$ arrays were prepared by anodic oxidizing method on the surface of the Ti substrate. Nitrogen-doped $\mathrm{TiO}_{2}$ nanotube $\left(\mathrm{N}-\mathrm{TiO}_{2} \mathrm{NT}\right)$ arrays were carried out by ammonia solution immersion, and $\mathrm{Ag}$ nanoparticles loaded $\mathrm{N}$-doped $\mathrm{TiO}_{2}$ nanotube $\left(\mathrm{Ag} / \mathrm{N}-\mathrm{TiO}{ }_{2} \mathrm{NT}\right)$ arrays were obtained by successive ionic layer adsorption and reaction (SILAR) technique. The samples were characterized by the $X$-ray diffraction (XRD), $X$-ray photoelectron spectroscopy (XPS), field emission scanning electron microscopy (FESEM), high-resolution transmission electron microscopy (HRTEM), photoluminescence (PL) emission spectra, ultraviolet-visible (UV-vis) diffuse reflectance spectroscopy (DRS). The result indicated that the diameter and wall thickness of the TiO ${ }_{2} \mathrm{NT}$ are 100-120 and 20-30 nm, respectively. Moreover, the morphology and structure of the highly ordered TiO ${ }_{2} \mathrm{NTS}_{\mathrm{s}}$ were not affected by $\mathrm{N}$-doping. Furthermore, Ag nanoparticles were evenly deposited on the surface of $\mathrm{TiO}_{2} \mathrm{NTS}$ in the form of elemental silver. Finally, the photocatalytic activity of $\mathrm{Ag} / \mathrm{N}-\mathrm{TiO}_{2} \mathrm{NTs}$ was evaluated by degradation of methyl orange (MO) under visible-light irradiation. The $\mathrm{Ag} / \mathrm{N}-\mathrm{TiO}_{2} \mathrm{NTs}$ exhibited enhanced photocatalytic properties, which could reach $95 \%$ after $90-$ min irradiation.
\end{abstract}

\section{Keywords:}

N-doped $\mathrm{TiO}_{2}$ NTs; Ag nanoparticle; visible light; photocatalysis

\section{Introduction}

Titanium dioxide $\left(\mathrm{TiO}_{2}\right)$ as a semiconductor has extensive application in the field of photocatalytic degradation of organic pollutants from dyeing and finishing because of its low cost, pollution-free, low toxicity, outstanding chemical stability, and unique photochemical properties [1-3]. $\mathrm{TiO}_{2}$ nanotubes $\left(\mathrm{TiO}_{2}\right.$ NTs) have attracted considerable attention in recent years because of their highly ordered structure, large surface area, strong pollutant adsorption, high photocatalytic activity, and convenient recycling when compared with conventional $\mathrm{TiO}_{2}$ powder [4-6].

However, the wide band gap of $\mathrm{TiO}_{2}$ is approximately $3.2 \mathrm{eV}$, leading to its photocatalytic activity only under UV light irradiation (about $5 \%$ of the solar light) and low catalytic efficiency in the visible light (about $42 \%$ of the solar light) [7]. In addition, the surface of $\mathrm{TiO}_{2}$ is lack of effective electron capture agent, and the photogenerated electron and hole are easy to compound in a short time, which leads to lower quantum efficiency and greatly limits its practical application [8, 9]. Various doping or modification attempts have been tried to improve its response to visible light, reduce photogenerated electron-hole pair recombination time, and improve the photocatalytic efficiency $[10,11]$.

Among the non-mental-doped $\mathrm{TiO}_{2}$ photocatalysts, nitrogendoped $\mathrm{TiO}_{2}$ is becoming more feasible and attractive to enhance the photocatalytic activity of $\mathrm{TiO}_{2}$ in the visible light region because of its comparable atomic size with oxygen and metastable center [12]. Besides, nitrogen-doping can narrow the band gap and shift the absorption edge of $\mathrm{TiO}_{2}$ to the visible region [13]. However, it is difficult to obtain $\mathrm{TiO}_{2}$ photocatalysts with high concentration of $\mathrm{N}$ dopants. Moreover, photogenerated carriers may try to recombine during the photocatalytic process for this $\mathrm{N}$ monodoping. Some researches showed that further modification of $\mathrm{N}$-doped $\mathrm{TiO}_{2}$ with transition or noble metal (e.g., Pt, Au, and $\mathrm{Ag}$ ) could improve the stability of the desired defects, reduce the recombination of an electron and hole, and improve the charge transfer efficiency $[14,15]$.

To our knowledge, there are few studies on the facile preparation of $\mathrm{Ag}$-loaded $\mathrm{N}$-doped $\mathrm{TiO}_{2}$ nanotube $\left(\mathrm{Ag} / \mathrm{N}-\mathrm{TiO}_{2}\right.$ NT) arrays and their photocatalytic activity [16-18]. In this study, anodic oxidizing method, ammonia solution immersion, and successive ionic layer adsorption and reaction (SILAR) method were used to prepare $\mathrm{Ag} / \mathrm{N}-\mathrm{TiO}_{2} \mathrm{NT}$ arrays. The morphologies, structures, and the photocatalytic properties of as-prepared materials were studied.

\section{Experimental}

\subsection{Synthesis of $\mathrm{N}$-doped $\mathrm{TiO}_{2}$ nanotube arrays}

$\mathrm{TiO}_{2} \mathrm{NTs}$ were prepared by anodization of Ti foils (99.8\% purity) at $50 \mathrm{~V}$ for $3 \mathrm{~h}$ in ethylene glycol solution containing $0.5 \mathrm{wt} . \%$ $\mathrm{NH}_{4} \mathrm{~F}$ and 3 vol. $\% \mathrm{H}_{2} \mathrm{O}$. After anodic oxidation, the as-prepared 
samples were immersed in $1 \mathrm{M} \mathrm{NH}_{3} \cdot \mathrm{H}_{2} \mathrm{O}$ solution for $12 \mathrm{~h}$ and annealed under ambient atmosphere at $450{ }^{\circ} \mathrm{C}$ for $1 \mathrm{~h}$ to obtain the $\mathrm{TiO}_{2} \mathrm{NTs}$ [14].

\section{$\underline{2.2 \text { Preparation of } \mathrm{Ag} / \mathrm{N}-\mathrm{TiO}_{2} \text { NTs }}$}

Ag nanoparticles were deposited on the $\mathrm{N}-\mathrm{TiO}_{2} \mathrm{NTs}$ by using SILAR process [16]. The $\mathrm{N}-\mathrm{TiO}_{2} \mathrm{NTs}$ were dipped into a $0.1 \mathrm{M}$ $\mathrm{AgNO}_{3}$ solution for $5 \mathrm{~min}$ and then dipped for another $5 \mathrm{~min}$ into a $0.1 \mathrm{M} \mathrm{NaBH}_{4}$ solution. This SILAR process was repeated for three cycles, which were denoted as $\mathrm{Ag} / \mathrm{N}-\mathrm{TiO}_{2} \mathrm{NTs}$.

\subsection{Characterizations}

The morphologies of the samples were observed by fieldemission scanning electron microscopy (FESEM, JOEL, JSM6700F) and transmission electron microscopy (TEM, Philips, and CM120). The crystal structure of samples was characterized by X-ray diffraction (XRD) technique (MAC Science Co. Ltd. MXP 18 AHF, CuKa). The surface chemical composition of samples was analyzed by X-ray photoelectron spectroscopy (XPS, PHI Quantum 2000). The photoluminescence (PL) emission spectra of the samples were measured at room temperature by Fluoromax-4 spectrofluorometer (USA).

\subsection{Photocatalytic activity test}

The photocatalytic activity of the as-prepared samples was evaluated by photocatalytic decomposition of $30 \mathrm{~mL}$ of methyl orange $(\mathrm{MO}, 10 \mathrm{mg} / \mathrm{L})$ aqueous solution under $250 \mathrm{~W}$ xenon lamp. The cut-off filters were used for obtaining visible light $(\lambda>400 \mathrm{~nm})$. The change in the concentration of MO was monitored by determining the UV-visible adsorption every 15 $\min$ at $464 \mathrm{~nm}$.
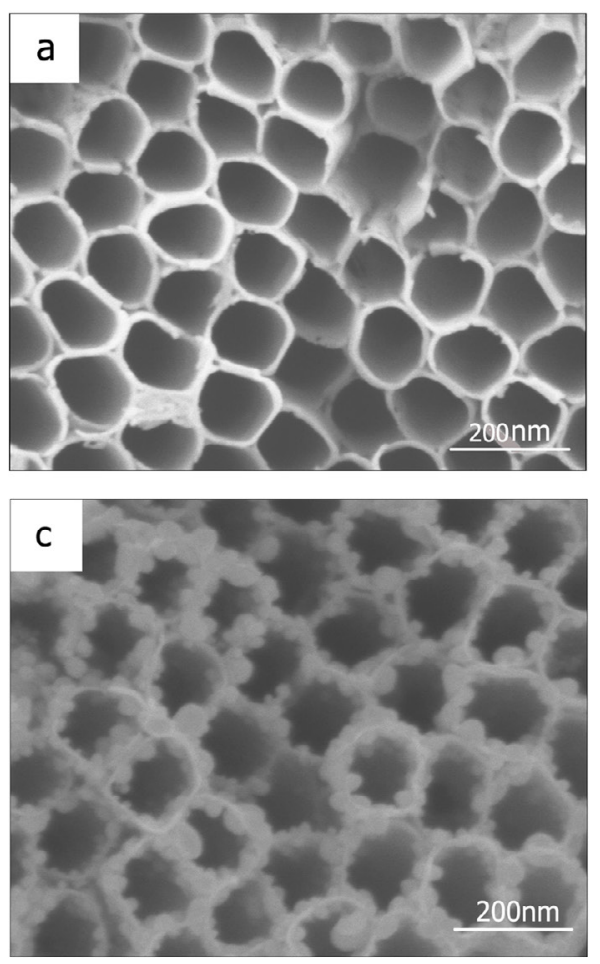

\section{Results and Discussion}

Figure 1a-d shows the typical scanning electron microscopy (SEM) and high-resolution transmission electron microscopy (HRTEM) images of both the as-prepared samples. From Figure $1 \mathrm{a}$ and $1 \mathrm{~b}$, it can seen that the samples had a clear vertical tubular structure with diameter of 110-130 nm, wall thickness of $15 \mathrm{~nm}$, and length of $17 \mu \mathrm{m}$. From Figure $1 \mathrm{~b}$, the ordered $\mathrm{TiO}_{2}$ NT arrays structure was well preserved after $\mathrm{N}$-doping. Figure 1c shows that the $\mathrm{Ag}$ nanoparticles have been successfully deposited on the surface of $\mathrm{TiO}_{2} \mathrm{NTs}$ with diameter of 10-60 nm. Because the defects or active sites are not evenly distributed on the nanotubes, there will be preferential deposition and growth of $\mathrm{Ag}$ on the surface of the nanotubes. Two different lattices with d spaces of 0.189 and $0.235 \mathrm{~nm}$ can be found from HRTEM images shown in Figure 1d, corresponding to the (200) plane of $\mathrm{TiO}_{2}$ and the (111) plane of Ag, respectively [19].

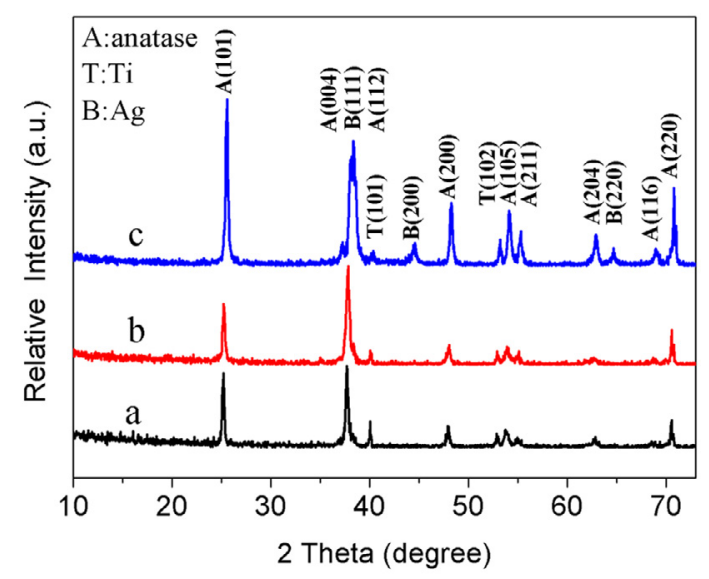

Figure 2. XRD patterns of (a) $\mathrm{TiO}_{2} \mathrm{NTs}$, (b) $\mathrm{N}-\mathrm{TiO}_{2} \mathrm{NTs}$, and (c) Ag/N$\mathrm{TiO}_{2} \mathrm{NTs}$.
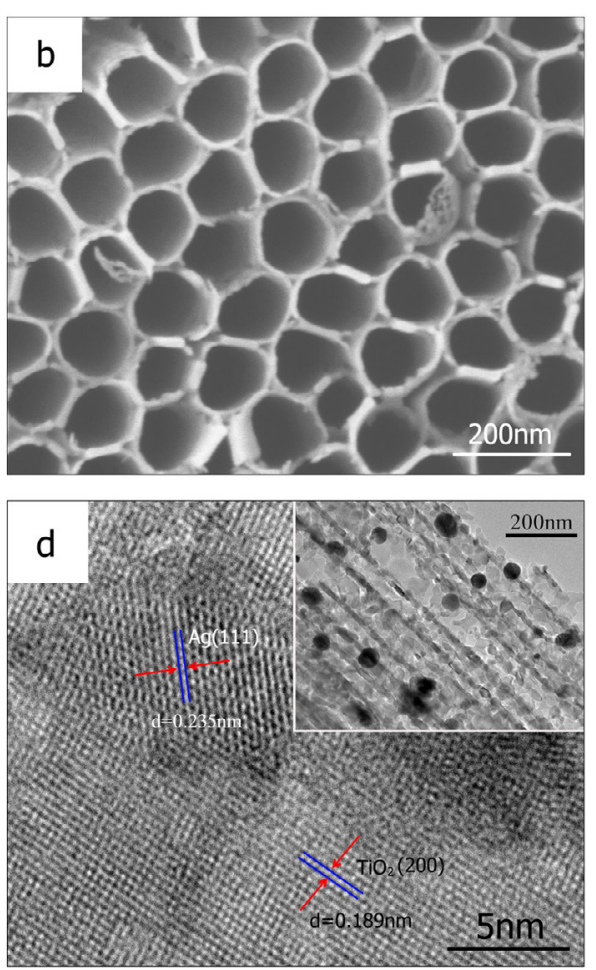

Figure 1. SEM and HRTEM image of (a) $\mathrm{TiO}_{2} \mathrm{NTs}$, (b)N-TiO ${ }_{2} \mathrm{NTs}$, (c \& d) Ag/N-TiO ${ }_{2} \mathrm{NTs}$. 
The XRD patterns of $\mathrm{TiO}_{2} \mathrm{NTs}, \mathrm{N}-\mathrm{TiO}_{2} \mathrm{NTs}$, and $\mathrm{Ag} / \mathrm{N}-\mathrm{TiO}_{2}$ NTs are shown in Figure 2. The diffraction peaks in the $40.5^{\circ}$ and $53.2^{\circ}$ are the characteristic peaks of the Ti substrate, corresponding to the (101) and (102) crystal faces of $\mathrm{Ti}$ substrate, respectively. The peaks with $2 \theta$ of $25.5^{\circ}, 37.1^{\circ}, 37.8^{\circ}$, $48.2^{\circ}, 54.1^{\circ}, 55.2^{\circ}, 62.9^{\circ}, 68.8^{\circ}$, and $70.6^{\circ}$ are assigned to the crystal structure of anatase $\mathrm{TiO}_{2}$ (JCPDS, card no: 21-1272), corresponding to planes (101), (004), (112), (200), (105), (211), (204), (116), and (220), respectively. The direction peaks at $38.3^{\circ}, 44.3^{\circ}$, and $64.7^{\circ}$ are in good agreement with the standard spectrum of elemental silver (JCPDS, card no: 04-0783), which can be indexed to $\mathrm{Ag}$ (111), (200), and (220), respectively. The average particle size was calculated by applying the Scherrer equation to the (101) diffraction plane of $\mathrm{TiO}_{2}: d=0.89 \lambda /(\beta \cos$ $\theta)$, where $d$ is the crystal size, $k$ is the constant $(0.89), \lambda$ is the $X$-ray wavelength $(1.54 \AA), \beta$ is the full width at half maximum (FWHM) of the Ag peaks, and $\theta$ is the diffraction angle. The calculated crystallite sizes of $\mathrm{TiO}_{2} \mathrm{NTs}, \mathrm{N}-\mathrm{TiO}_{2} \mathrm{NTs}$, and $\mathrm{Ag} /$ $\mathrm{N}-\mathrm{TiO}_{2} \mathrm{NTs}$ are 31.22, 27.92, and $28.06 \mathrm{~nm}$, respectively. It reveals that $\mathrm{N}$-doping inhibits the growth of the titania crystallite during thermal process, while the effect of $\mathrm{Ag}$ loading on the crystallite sizes of $\mathrm{TiO}_{2}$ is not obvious.

The chemical composition and chemical states of $\mathrm{Ag} / \mathrm{N}-\mathrm{TiO}_{2}$ NTs were examined by XPS, as shown in Figure 3a-e. Figure $3 b$ shows the full-scale XPS survey spectrum of the hybrid samples, which indicates the existence of $\mathrm{C}, \mathrm{Ti}, \mathrm{O}, \mathrm{Ag}$, and $\mathrm{N}$. The presence of $\mathrm{C} 1 \mathrm{~s}$ is mainly due to the pollution caused during the sample preparation process and by the XPS instrument itself [20]. Figure 3b demonstrates the N1s XPS spectrum of the $\mathrm{Ag} / \mathrm{N}-\mathrm{TiO}_{2} \mathrm{NTs}$. The N1s XPS peak with a core level binding energy of $399.8 \mathrm{eV}$ can be assigned to the interstitial nitrogen atoms in crystal lattice of $\mathrm{TiO}_{2}$ as $\mathrm{O}-\mathrm{Ti}-\mathrm{N}$ structural feature instead of molecularly chemisorbed $\mathrm{N}$ species on the surface of $\mathrm{TiO}_{2} \mathrm{NTs}[21,22]$. It reveals that $\mathrm{N}$ dopants may be stable because of the tendency of electron transfer from the oxygen vacancies to the partially occupied and lower energy $\mathrm{N} 2 \mathrm{p}$ states [23]. As shown in Figure 3c, binding energies of 458.2 and $464.4 \mathrm{eV}$ are ascribed to the peaks of $\mathrm{Ti} 2 \mathrm{p}_{3 / 2}$ and $\mathrm{Ti}$ $2 p_{1 / 2}$, respectively. They are assigned to the lattice of titanium in $\mathrm{TiO}_{2}$ corresponding to a $2 \mathrm{p} 3$ binding energy of $\mathrm{Ti}$ (IV) ion. The deconvolution of O1s XPS spectrum in Figure 3d gives two peaks centered at 531.1 and $530.0 \mathrm{eV}$. In addition to the substitutional $\mathrm{N}$, it further confirms the formation of the O-Ti-N structure. Figure $3 \mathrm{e}$ shows the XPS spectrum of Ag3d regions. The two peaks located at 373.6 and $367.7 \mathrm{eV}$ are originated from $A g 3 d_{5 / 2}$ and $A g 3 d_{3 / 2}$, respectively. The splitting of the $3 d$ doublet is $6.0 \mathrm{eV}$, which indicates that the $\mathrm{Ag}$ loading on the $\mathrm{TiO}_{2}$ surface mainly exists as the $\mathrm{Ag}^{\circ}$ state [24]. Moreover, the Ag loading could further stabilize the $\mathrm{N}$ dopants in the oxide because of the electron transfer from the $\mathrm{Ag} 5 \mathrm{~s}$ orbitals to the $2 p$ orbitals of the implanted $N$ [25].

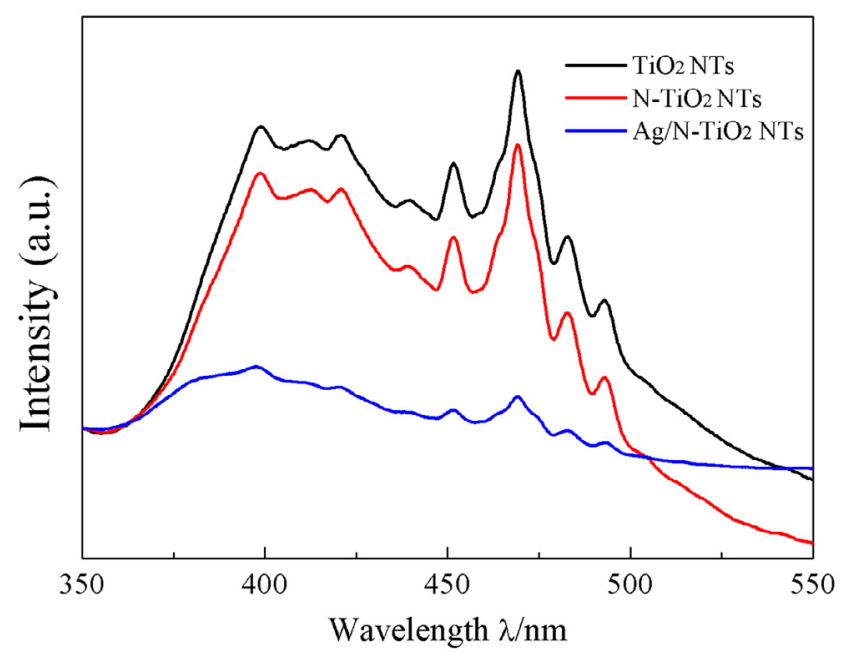

Figure 4. Photoluminescence emission spectra of the samples
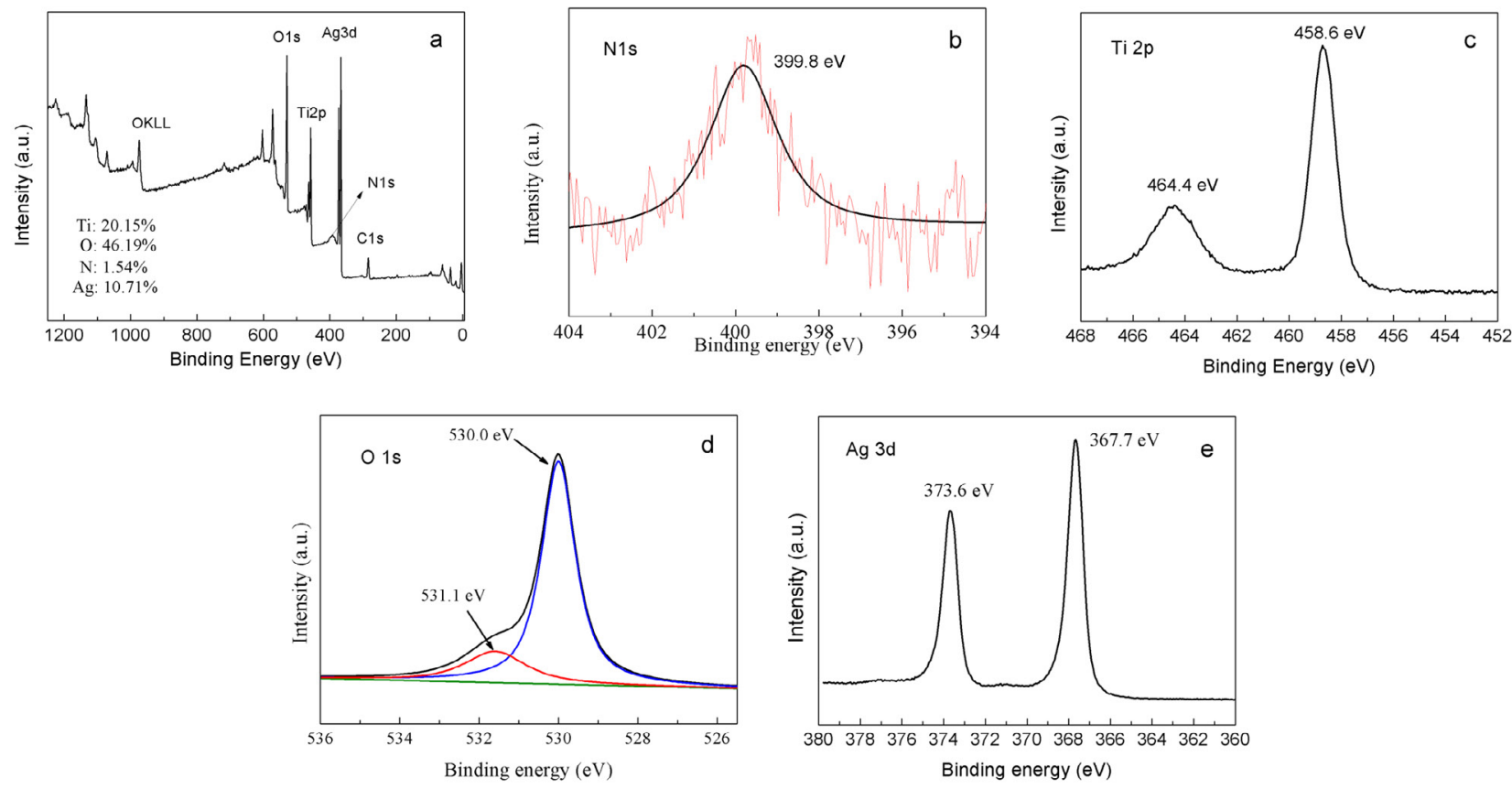

Figure 3. XPS survey spectra of (a) Ag/N-TiO 2 NTs and XPS high-resolution spectra of (b) N1s, (c) Ti2p, (d) O1s, and (e) Ag3d. 
The fluorescence emission spectra of $\mathrm{TiO}_{2} \mathrm{NTs}, \mathrm{N}-\mathrm{TiO}_{2} \mathrm{NTs}$, and $\mathrm{Ag} / \mathrm{N}-\mathrm{TiO}_{2} \mathrm{NTs}$ excited by 300-nm laser are shown in Figure 4. Each sample showed a strong and broad emission signal within the scope of $350-550 \mathrm{~nm}$, and two excitation peaks at 400 and $470 \mathrm{~nm}$ were clearly exhibited, which may be caused by the free exciton luminescence of band edge and the bound exciton luminescence originating from oxygen vacancies and defects on the surface of nanocrystalline [26, 27]. Compared with $\mathrm{TiO}_{2} \mathrm{NTs}$, the peak intensity of $\mathrm{N}-\mathrm{TiO}_{2} \mathrm{NTs}$ was reduced to a certain extent. This is due to the impurity energy level introduced to the top of $\mathrm{TiO}_{2}$ valence band, and the separation of photogenerated electrons and holes from vacancies can be effectively promoted. The peak intensity of $\mathrm{Ag} / \mathrm{N}-\mathrm{TiO}_{2} \mathrm{NTs}$ decreased significantly compared with $\mathrm{N}-\mathrm{TiO}_{2} \mathrm{NTs}$, which indicates that the separation efficiency of photogenerated carriers was further improved because of the synergetic effect of $\mathrm{Ag}$ and $\mathrm{N}$. It is showed that the fluorescence intensity is positively correlated with the recombination rate of electronhole pairs, and $\mathrm{Ag} / \mathrm{N}-\mathrm{TiO}_{2} \mathrm{NTs}$ has the highest photocatalytic efficiency, which can be proved from photocatalytic degradation test of MO solution.

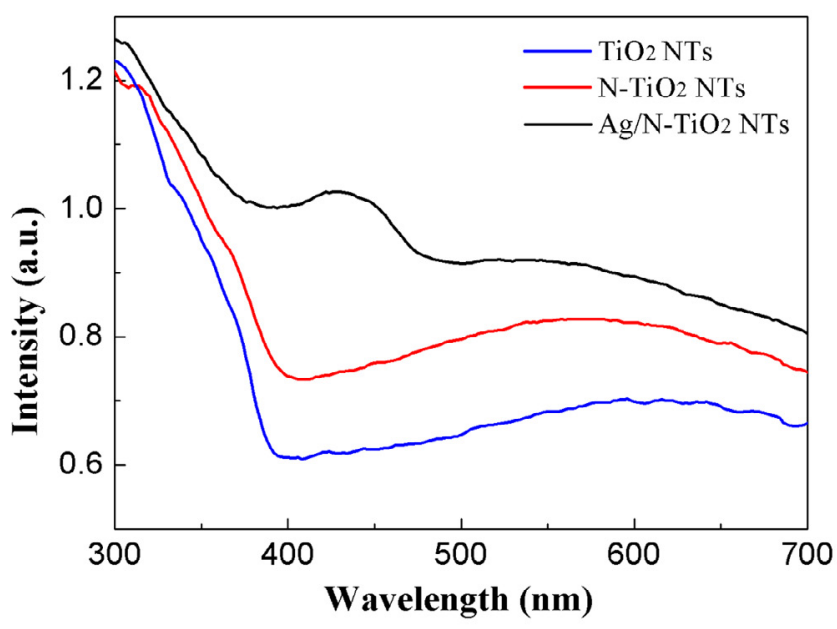

Figure 5. UV-vis absorption spectra of the samples

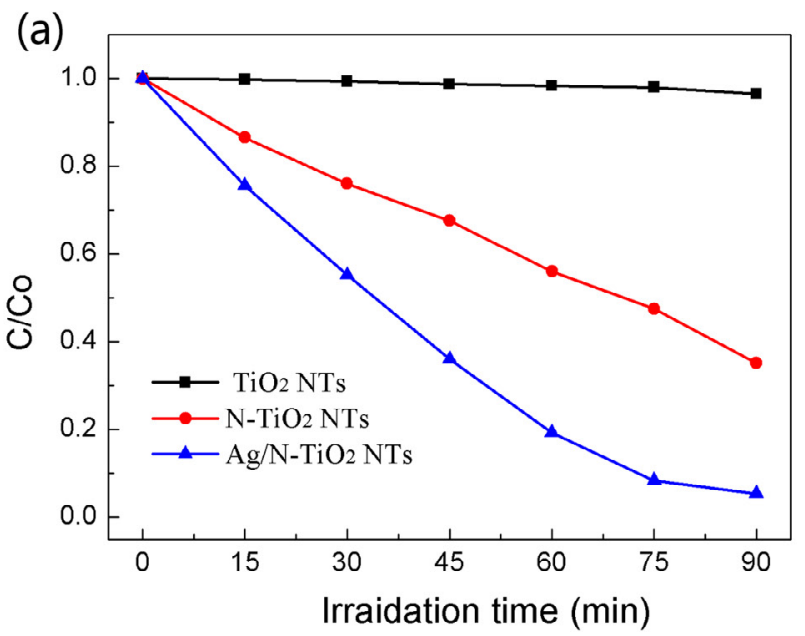

Figure 5 shows the UV-vis absorption spectra of $\mathrm{TiO}_{2} \mathrm{NTs}$, $\mathrm{N}-\mathrm{TiO}_{2} \mathrm{NTs}$, and $\mathrm{Ag} / \mathrm{N}-\mathrm{TiO}_{2} \mathrm{NTs}$. It can be observed from Figure 5 that the strong absorption below $400 \mathrm{~nm}$ for the $\mathrm{TiO}_{2}$ NTs is due to the intrinsic interband transition absorption of $\mathrm{TiO}_{2}$. The absorption of $\mathrm{TiO}_{2} \mathrm{NTs}$ in the visible region can be attributed to the scattering of light caused by pores or cracks in the nanotube arrays [28]. Compared with $\mathrm{TiO}_{2} \mathrm{NTs}, \mathrm{N}-\mathrm{TiO}_{2}$ NTs show stronger visible-light absorbance and a slight redshift owing to the stable oxygen vacancies on the surface and interaction between N $2 p$ and $O 2 p$ orbit [29]. Moreover, the optical absorption edge of the $\mathrm{Ag} / \mathrm{N}-\mathrm{TiO}_{2} \mathrm{NTs}$ also extends to the visible region with an obvious visible-light absorption peak at $425 \mathrm{~nm}$ indicating $\mathrm{Ag}$ nanoparticles, which could be ascribed to the synergistic effect of $\mathrm{Ag}, \mathrm{N}$, and $\mathrm{TiO}_{2}$ [30].

Figure 6a shows the photocatalytic activity of photocatalysts under visible light. The result showed that the degradation rate from high to low in sequence was $\mathrm{Ag} / \mathrm{N}-\mathrm{TiO}_{2} \mathrm{NTs}, \mathrm{N}-\mathrm{TiO}_{2} \mathrm{NTs}$, and $\mathrm{TiO}_{2} \mathrm{NTs}$. It is obvious that the $\mathrm{Ag} / \mathrm{N}-\mathrm{TiO}_{2} \mathrm{NTs}$ has the best photocatalytic ability. $\mathrm{TiO}_{2} \mathrm{NTs}$ had almost no photocatalytic activity of visible light, which can only be activated under UV light. The degradation rates after 90 min were increased to $66 \%$ and $95 \%$, respectively. The increasing photocatalytic activity indicates that $\mathrm{N}$-doping may enhance the separation and transferring efficient of the photogenerated carriers [31]. $\mathrm{Ag}$ nanoparticles were applied to act as electron reservoirs to suppress the electron-hole recombination, and more holes were available for the oxidation reactions. The enhanced photocatalytic properties for the $\mathrm{Ag} / \mathrm{N}-\mathrm{TiO}_{2} \mathrm{NTs}$ in visible region were attributed to the localized surface plasmon resonance effect and synergistic effect between $\mathrm{Ag}$ nanoparticles and $\mathrm{N}-\mathrm{TiO}_{2} \mathrm{NTs}$. Thus, the $\mathrm{Ag} / \mathrm{N}-\mathrm{TiO}_{2} \mathrm{NTs}$ demonstrated the highest photocatalytic activity toward the degradation of $\mathrm{MO}$, which was consistent with the fluorescence quenching effect revealed by PL spectra in Figure 4.

Figure $6 b$ demonstrates the kinetic behaviors of the MO photodegradation by these photocatalysts. The degradation reactions for the samples are in accord with the first-order

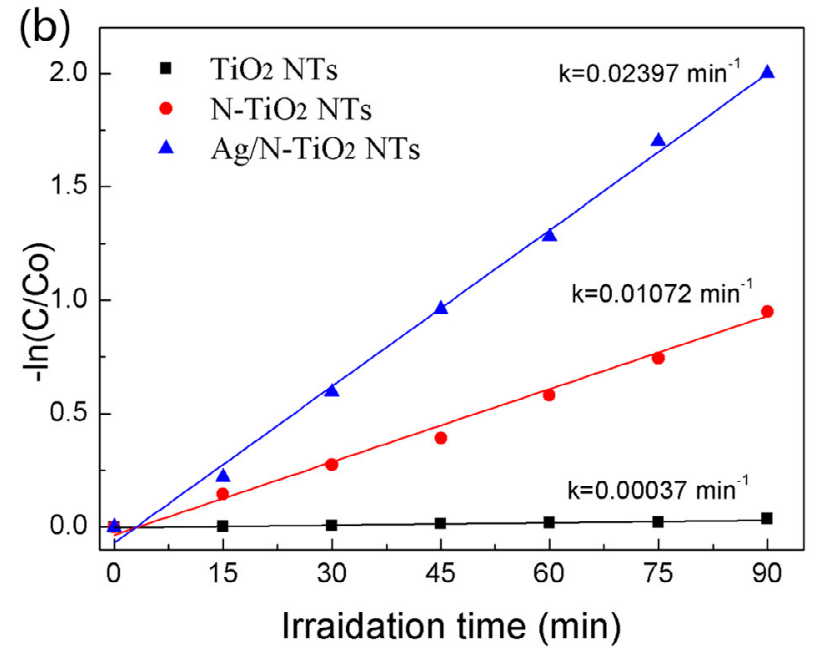

Figure 6. (a) The degradation rate of $\mathrm{MO}$ against irradiation time under visible light; (b) plots of $-\ln \left(\mathrm{C} / \mathrm{C}_{0}\right)$ versus irradiation time for $\mathrm{MO}$ representing the fit using a pseudo-first-order reaction rate. 
kinetic equation $\left(\ln \left(C / C_{0}\right)=-k t\right)$, where the slope $k, C$, and $C_{0}$ are the photocatalytic reaction constant, the actual concentration of the $\mathrm{MO}$, and initial concentration of the $\mathrm{MO}$, respectively. In comparison, the apparent rate constant for $\mathrm{Ag} / \mathrm{N}-\mathrm{TiO}_{2} \mathrm{NTs}$ $\left(0.02397 \mathrm{~min}^{-1}\right)$ is much greater than the $\mathrm{N}-\mathrm{TiO}_{2} \mathrm{NTs}$ and $\mathrm{TiO}_{2}$ NTs (0.01072 and $0.00037 \mathrm{~min}^{-1}$, respectively), which means the higher.

\section{Conclusions}

In summary, the $\mathrm{N}-\mathrm{TiO}_{2} \mathrm{NTs}$ have been successfully fabricated directly by anodic oxidation of Ti foils, followed by ambient heat treatment of the $\mathrm{TiO}_{2} \mathrm{NTs}$ pre-soaked in ammonia solution. Then, Ag nanoparticles were successfully introduced into the $\mathrm{N}-\mathrm{TiO}_{2} \mathrm{NTs}$ by the ionic layer adsorption and reaction route. $\mathrm{TiO}_{2}$ $\mathrm{NTs}$ are in good tubular structure after $\mathrm{N}$-doping, and nitrogen atoms were successfully incorporated into the interstitial sites of the $\mathrm{TiO}_{2}$ crystal lattice, while Ag mainly existed in the form of zero valence and makes the $\mathrm{N}$ dopants stable during the photocatalytic process. The photocatalytic degradation rate of $\mathrm{Ag} / \mathrm{N}-\mathrm{TiO}_{2} \mathrm{NTs}$ was increased by $95 \%$ compared with that of unmodified $\mathrm{TiO}_{2}$. It is considered that the $\mathrm{Ag}$ and $\mathrm{N}$ co-doped $\mathrm{TiO}_{2} \mathrm{NTs}$ significantly exhibited a synergistic effect on the improvement of the photocatalytic capability in degrading $\mathrm{MO}$ dye under visible light irradiation.

\section{Acknowledgments}

This work is financially supported by the National Natural Science Foundation of China (Grant No. 21403184), Natural Science Foundation of the Jiangsu Higher Education Institutions of China (Grant No. 14KJB150025 and 5KJB430032), China Postdoctoral Science Foundation (No. 2014M561622), and the Joint Research Fund between Collaborative Innovation Center for Ecological Building Materials and Environmental Protection Equipments and Key Laboratory for Advanced Technology in Environmental Protection of Jiangsu Province (GX2015205).

\section{References}

[1] Eperon G. E., Burlakov V. M., Docampo P., Goriely A., Snaith H.J. (2014). Morphological control for high performance, solution-processed planar heterojunction perovskite solar cells. Adv. Funct. Mater., 24, 151-157.

[2] Mei A., Li X., Liu L., Ku Z., Liu T., Rong Y., Xu M., Hu M. (2014). A hole-conductor-free, fully printable mesoscopic perovskite solar cell with high stability. Science, 345, 295-8.

[3] Xu G., Liu H., Wang J., Lv J., Zheng Z., Wu Y. (2014). Photoelectrochemical Performances and Potential Applications of TiO2 Nanotube Arrays Modified with Ag and Pt Nanoparticles. Electrochim. Acta, 121, 194-202.

[4] Lan C. S., Leong K. H., Ibrahim S., Saravanan P. (2014) Graphene oxide and $\mathrm{Ag}$ engulfed TiO2 nanotube arrays for enhanced electron mobility and visible-light-driven photocatalytic performance. J. Mater. Chem. A, 2, 53155322.

[5] Yu D., Zhu X., Xu Z., Zhong X., Gui Q., Song Y. (2014) Facile Method to enhance the adhesion of TiO2 nanotube arrays to Ti substrate. ACS App.I Mater. Inter., 6, 8001-8005.
[6] Park H., Lee J., Park T., Lee S., Yi W. (2015). Enhancement of photo-current conversion efficiency in a CdS/CdSe quantumdot-sensitized solar cell incorporated with single-walled carbon nanotubes. J. Nanosci. Nanotechno., 15, 1614-1617.

[7] Fang-Xing X., Hung S.-F., Miao J., Wang H. Y., Yang $H$. (2015). Metal-Cluster-Decorated TiO2 Nanotube Arrays: A Composite Heterostructure toward Versatile Photocatalytic and Photoelectrochemical Applications. Small, 11, (5), 554-567.

[8] Kilinc N., sennik E., Isik M., Ahsen A. S., Öztürk O., Öztürk, Z. Z. (2014). Fabrication and gas sensing properties of C-doped and un-doped TiO2, nanotubes. Ceram. Int., 40, (1), 109-115.

[9] 9.. Luo J., Chen J., Wang H., Liu H. (2016). Ligandexchange assisted preparation of plasmonic Au/TiO2 nanotube arrays photoanodes for visible-light-driven photoelectrochemical water splitting. J. Power. Sources, 303, 726-729.

[10] Chen X., Song Y., Lu L., Cheng C., Liu D., Fang X. (2013). Electrochemically hydrogenated TiO2 nanotubes with improved photoelectrochemical water splitting performance. Nanoscale Res. Lett., 8, (1), 1-7.

[11] Fang X. X., Hung S. F., Miao J., Wang H., Yang H., Liu B. (2015). Metal-cluster-decorated TiO2 nanotube arrays: a composite heterostructure toward versatile photocatalytic and photoelectrochemical applications. Small, 11, 554-567.

[12] Gao Y., Fang P., Chen F., Liu Y., Liu Z. (2013). Enhancement of stability of N-doped TiO2 photocatalysts with Ag loading [J]. Appl. Surf. Sci., 265, 796-801.

[13] Cheng X., Cheng Q., Li B., Deng X., Li J. (2015). Onestep construction of N/Ti3+ co-doped TiO2 nanotubes photoelectrode with high photoelectrochemical and photoelectrocatalytic performance. Electrochim. Acta, 186, :442-448.

[14] lliev V., Tomova D., Rakovsky S. (2010). Nanosized $\mathrm{N}$-doped TiO2, and gold modified semiconductorsphotocatalysts for combined UV-visible light destruction of oxalic acid in aqueous solution[J]. Desalination, 260, (1-3), 101-106.

[15] Wu R. J., Hsieh Y. C., Hung H. C. (2014). Visible Light Photocatalytic Activity of Pt/N-TiO2 towards Enhanced H2 Production from Water Splitting. J. Chin. Chem. Soc., 61(4), 495-500.

[16] Gao Y., Fang P., Chen F., Liu Y., Liu Z., Wang D. (2013). Enhancement of stability of N-doped TiO2 photocatalysts with Ag loading. Appl. Surf. Sci., 265, 796-801.

[17] Yang S., Wang H., Yu H., Zhang S., Fang Y. (2016). Zhang S., A facile fabrication of hierarchical Ag nanoparticlesdecorated N-TiO2 with enhanced photocatalytic hydrogen production under solar light. Int. J. Hydrogen Energy, 41, 3446-3455.

[18] Zhang S., Peng F., Wang H., Yu H., Zhang S., Yang J. (2011). Electrodeposition preparation of $\mathrm{Ag}$ loaded $\mathrm{N}$-doped TiO2 nanotube arrays with enhanced visible light photocatalytic performance. Catal. Commun., 12, 689693.

[19] Liang Y., Cui Z., Zhu S., Liu Y., Yang X. (2011). Silver nanoparticles supported on $\mathrm{TiO} 2$ nanotubes as active catalysts for ethanol oxidation. J. Catal., 278, 276-287.

[20] Liu G., Jaegermann W., He J., Sundström V., Sun L. (2002). XPS and UPS characterization of the TiO2/ ZnPcGly heterointerface: alignment of energy levels. J. Phys. Chem. B, 106, 5814-5819. 
[21] Yuan Y., Ding J., Xu J., Deng J., Guo J. (2010). TiO2 nanoparticles co-doped with silver and nitrogen for antibacterial application. J. Nanosci. Nanotechno., 10, 4868-4874.

[22] Peng F., Cai L. F., Yu H., Wang H., Yang J. (2008). Synthesis and characterization of substitutional and interstitial nitrogen-doped titanium dioxides with visible light photocatalytic activity. J. Solid. State Chem., 181, 130-136.

[23] Antony R. P., Mathews T., Panda K. (2012). Enhanced Field Emission Properties of Electrochemically Synthesized Self-Aligned Nitrogen-Doped TiO2 Nanotube Array Thin Films. J. Phys. Chem. C, 116(31):16740-16746.

[24] Yu J. G., Xiong J. F., Cheng B., Liu S. (2005). Fabrication and characterization of Ag-TiO2 multiphase nanocomposite thin films with enhanced photocatalytic activity. Appl. Catal. B-Environ., 60, 211-221.

[25] Gao Y., Fang P., Chen F., Liu Y., Liu Z. (2013). Enhancement of stability of $\mathrm{N}$-doped TiO2 photocatalysts with Ag loading. Appl. Surf. Sci., 265, 796-801.

[26] Sun T.; Fan J.; Liu E.; Liu L.; Wang Y.; Dai H. (2012). Fe and Ni co-doped TiO2, nanoparticles prepared by alcoholthermal method: Application in hydrogen evolution by water splitting under visible light irradiation. Powder Technol., 228, 210-218.

[27] Niishiro R., Kato H., Kudo A. (2005). Nickel and either titanium or niobium co-doped $\mathrm{TiO} 2$ and $\mathrm{SrTiO} 3$ photocatalysts with visible-light response for $\mathrm{H} 2$ or $\mathrm{O} 2$ evolution from aqueous solutions. P. C. C. P., 7, 22412245 .
[28] Zhang S., Peng F., Wang H., Yu H., Zhang S. (2011). Electrodeposition preparation of Ag loaded N-doped TiO2 nanotube arrays with enhanced visible light photocatalytic performance. Catalysis Communications, 12, (8), 689-693.

[29] Song X., Gao L. (2007). Synthesis, characterization, and optical properties of well-defined $\mathrm{N}$-doped, hollow silica/ titania hybrid microspheres. Langmuir, 23, (23), 1185011856.

[30] Yang S., Wang H., Yu H., Zhang S., Fang Y. (2016). A facile fabrication of hierarchical Ag nanoparticles-decorated $\mathrm{N}$-TiO2 with enhanced photocatalytic hydrogen production under solar light. Int. J. Hydrogen Energy, 41, (5), 34463455.

[31] Lan M., Zhang Y., Wang P. N. (2008). First-principles study of the hydrogen doping influence on the geometric and electronic structures of N-doped TiO2. Chem. Phys. Lett., 458, 341-345.

[32] Dong P., Wang Y., Cao B., Xin S., Guo L.(2013). Ag3PO4/ reduced graphite oxide sheets nanocomposites with highly enhanced visible light photocatalytic activity and stability. Appl. Catal. B Environmental, 132-133, (9), 45-53.

[33] Zhang Q., Wang L., Feng J., Xu H., Yan W. (2014). Enhanced photoelectrochemical performance by synthesizingCdS decorated reduced TiO2 nanotube arrays. Phys. Chem. Chem. Phys., 16, (42), 23431-23439. 